\title{
Design and Simulation of a Low-Actuation-Voltage MEMS Switch
}

\author{
Yasser Mafinejad \\ School of Engineering \\ Deakin University \\ Waurn Ponds \\ Victoria 3216, Australia \\ ymafinej@deakin.edu.au
}

\author{
Abbas Z. Kouzani \\ School of Engineering \\ Deakin University \\ Waurn Ponds \\ Victoria 3216, Australia \\ kouzani@deakin.edu.au
}

\author{
Ladislau Matekovits \\ Department of Electronics and \\ Telecomunications \\ Politecnico di Torino \\ Torino 10129 Italy \\ ladislau.matekovits@polito.it
}

\begin{abstract}
This paper presents a low-actuation-voltage micro-electromechanical system (MEMS) capacitive shunt switch which has a very large bandwidth ( $4 \mathrm{GHz}$ to $24 \mathrm{GHz}$ ). In this work, the isolation of MEMS switch is improved by adding two short high impedance transmission lines at the beginning and end of a coplanar waveguide (CPW). Simulating the switch demonstrates that a return loss ( $\mathrm{S} 11)$ is less than $-26 \mathrm{~dB}$ for the entire frequency band, and perfect matching at $20 \mathrm{GHz}$ in upstate position. A ramp dual pulse driver is also designed for reducing the capacitive charge injection for considering the reliability of the switch. The simulation results show that the shifting of voltage due to the capacitive charge is reduced by more than $35 \%$ of the initial value. Finally, the dynamic behavior of the MEMS switch is simulated by modal analysis and using CoventorWare to calculate the natural frequencies of the switch and its mode shapes. The switching ON and OFF time are 4.48 and $2.43 \mu \mathrm{s}$, respectively, with an actuation voltage of less than $15 \mathrm{~V}$.
\end{abstract}

\section{Categories and Subject Descriptors}

C.2.1 [Computer-Communication Networks]: Network Architecture and Design - wireless communication.

\section{General Terms}

Measurement, Performance, Design, Experimentation.

\section{Keywords}

RF MEMS, switch, low-actuation-voltage, capacitive, shunt.

\section{INTRODUCTION}

The advancement of micro/nano electro mechanical systems (MEMS/NEMS) has enabled integration of MEMS switches and electronic devices on the same substrate in order to serve for low power consumption, high electrical isolation and ultra wide frequency band applications [1-4].
Radio frequency (RF) MEMS switches are categorized into four groups based on their types of actuation: piezoelectric, electrothermal, electro-magnetic and electrostatic. The piezoelectric switch uses piezo materials such as AlN or PZT between two electrodes of beam or membrane [5]. The electro-thermal switch bonds material with different expansion coefficients to their beam $[2,6]$. The electro-magnetic switch uses electro-magnetic force (EM). This force is created by applying a current element with in the magnetic field through the coil on top of the membrane. There is a very interesting EM RF MEMS switch proposed by Cho et al. [7] with an actuation voltage of $3 \mathrm{~V}$ and a very high isolation bandwidth (-54 and $-36 \mathrm{~dB}$ at 2 and $20 \mathrm{GHz}$ respectively). The gap between transmission line and beam is $10 \mu \mathrm{m}$. The fourth group is electrostatic (ES) switch. This type of switch is the most popular switch compared to other types of switches from the standpoints of fabrication, switching time, reliability and frequency bands. However, unlike the other types of switches which have the actuation voltage less than $15 \mathrm{~V}$, ES RF MEMS switches have a very high actuation voltage $(>50 \mathrm{~V})[8]$.

Over the past decade, many researchers have demonstrated modular approaches to reduce the actuation voltage of electrostatic RF MEMS switches to be able to integrate them with electronic devices. Different methods have been used for reducing the actuation voltage of RF MEMS electrostatic MEMS switch. The first method for reducing the actuation voltage is to increase the electrostatic force. This can be done by using three states switches (ON, OFF and neutral) [9]. This type of switch consists of a beam which is anchored to a pillar at the middle while both ends are free. It also uses two separate voltage sources to provide negative and positive voltages. While voltages are applied to either of the electrodes, large positive deflection is then noticed on one side and smaller negative deflection with a large contact area is obtained on the other side. However, there are some issues with this method. Firstly, it uses the RIE etching instead of the wet etching, and also requires more fabrication steps than the normal MEMS switches for patterning pillars. Moreover, it requires two voltage sources which increase the power loss. The second method for increasing the force is a comb switch. It uses a comb driver which consists of stationary and movable fingers to provide a large electrostatic force. However, most of the reported RF MEMS comb switches have a DC contact and less capacitive contact. These are due to the deposition of dielectric on the side walls which limits the $\mathrm{ON}$ and OFF capacitance ratio. Moreover, the switching time for this type of switches is high due to the bulky and heavy comb drivers [10, 11]. The second method for reducing the actuation voltage is to reduce the spring constant. This can be achieved by movable 
membrane and transmission line [12], or low spring constant. Although these techniques reduce the actuation voltage, they negatively affect the switching time [13]. The third method for reducing the actuation voltage is to use carbon nanotube (CNT) materials such as single wall carbon nanotube arrays for membrane $[14,15]$, multi wall carbon nanotube [16] or graphene [17, 18] instead of metal alloys. These types of switches are called RF NEMS carbon based switches [19] and have a very low actuation voltage due to the effect of van deer Waals force. The switching time of these switches is very low (ns) [20], but their fabrication process is extremely hard. There are only a few reports on RF parameters of NEMS switches.

The aim of this research work is to design a low ES actuation voltage (less than $15 \mathrm{~V}$ ) and also a very high isolation multipurpose switch with a very large bandwidth to cover the hiperlan mobile frequency till RF receivers of satellite communication. This method of design provides two main advantages compared to other methods: Firstly, it does not affect mechanical parameters of the switch such as switching time or spring constant. Secondly, it uses convenient fabrication processes which are used for MEMS switches such as soft lithography, wet etching and sputtering. It does not have any additional lithography process. We also propose a convenient electrical model for further analyzing the whole circuit. The validity of the electrical model is verified by simulation and analytical calculation.

\section{PARAMETERS of MEMS SWITCHES}

Any RF MEMS capacitive shunt switch consists of two essential parts: a transmission line and a bridge. The transmission line is a Coplanar Waveguide (CPW) or a microstrip line for transferring the signal from the input to the output of the switch. The bridge can be a fixed-fixed or a cantilever which are anchored to the ground. The performance of the switch depends on their RF parameters, mechanical parameters and reliability of the switch.

\subsection{RF Parameters}

The validity of the RF parameters of the switch is verified by the scattering parameters in the desired frequency band by the simulation or analysis of the electrical circuit model. The value of the lumped elements of the electrical model can be calculated through the physical structure of the switch or determined from the scattering parameter at the convenient frequencies. The parasitic element of the model cannot be easily neglected because the frequency band is extra wide $(4-24 \mathrm{GHz})$. The performance of the MEMS switches strongly depends on the ratio of capacitance at up and down state. At the up state position while the parallel switch is $\mathrm{ON}$, the switch should be matched with input and output. The values of $S_{11}$ equals or less than $-10 \mathrm{~dB}$ providing acceptable matching at the input in the up-state position (Eq. (1)), and while the switch is OFF (down state), signal should not be transferred from the input to the output $\left(\mathrm{S}_{21} \leq-10 \mathrm{~dB}\right)$ (Eq. (2)).

$$
\begin{gathered}
\mathrm{S}_{11} \text { (sup state) }=\frac{-j \omega c_{u p} Z_{0}}{2+j \omega c_{u p} Z_{0}} \\
\mathrm{~S}_{21}\left(\text { up state) }=\frac{1}{1+j \omega c_{\mathrm{d}} Z_{0} / 2}\right.
\end{gathered}
$$

Another parameter which affects the RF performances of MEMS switches is the resistivity of material owing to the effect of the skin depth on the transmission line and the bridge. The thickness of the gold transmission line (TL) and bridge should be more than $2 \mu \mathrm{m}$ and between $0.5-1 \mu \mathrm{m}$ respectively.

\subsection{Mechanical Parameters}

The mechanical behavior of MEMS switches depends on the mode shapes and the frequencies of each mode. Modal analysis is used to predict the mode shapes and natural frequencies of each mode. This paper investigates a type of clamped-clamped beam. The dynamic model and natural frequency of MEMS switch for a fixed-fixed beam are given below. More information is provided in ref. [2123].

$$
\varphi_{i}(x)=A_{i} \cos \left(\beta_{i} x\right)+B_{i} \sin \left(\beta_{i} x\right)+C_{i} \cosh \left(\beta_{i} x\right)+D_{i} \sinh \left(\beta_{i} x\right)
$$

where $A_{i}, B, C_{i}$, and $D_{i}$ are calculated through the boundary conditions for a fixed-fixed beam and an is the frequency. The boundary condition for fixed-fixed MEMS switch is:

$$
y=\frac{d y}{d x}=0 \quad \text { at } x=0, y=\frac{d y}{d x}=0 \quad \text { at } x=L
$$

Therefore, the characteristic equation and natural frequency are:

$$
\omega_{n}=\frac{\beta_{n}^{2}}{L^{2}} \sqrt{\frac{E I}{m}} \text { for } \beta_{n}=a_{n}=\frac{2 n+1}{2} \pi
$$

The switching times of MEMS switches is limited by the mechanical structure, and it is likely to keep the resonant frequency of MEMS switches less than the first natural frequency of MEMS switch. Although a high natural frequency may also lead to an increased switch-on time, the shape mode of the beam is not useful for RF MEMS switches. The relation between the switching time and the natural frequency of MEMS switch is given as bellow [24].

$$
\begin{gathered}
t_{\text {ON }}(\text { pull }- \text { in condition })=0.46 f_{N}^{-1} \\
t_{\text {OFF }}(\text { pull }- \text { out condition })=0.25 f_{N}^{-1}
\end{gathered}
$$

The relation between gap and voltage source is shown in Figure 1. Increasing the actuation voltage $\left(\mathrm{V}_{\text {pull-in }}\right)$ makes instability and causes the upper electrode to snap down at $\mathrm{V}_{\text {pull-in. }}$. Electrostatic force relies on a voltage source and a capacitor between the TL and the membrane (Eq. (8)). The membrane still in down state until $\mathrm{V}_{\text {pull-out }}$ due to the wan deer Waals force. The upper electrode is released at the pull out voltage because of the elastic force (Eq. (9)) [25-27].

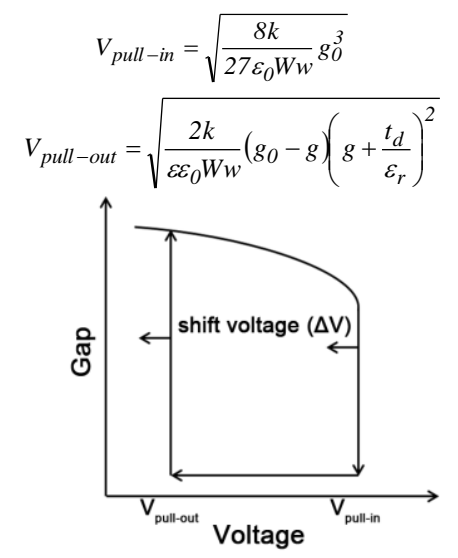

Figure 1. $V_{\text {pull-in }}$ and $V_{\text {pull-out }}$ of RF MEMS switches. 


\subsection{Reliability}

The dielectric charging is the main failure mechanism in the lifetime of the electrostatically actuated capacitive RF MEMS switches. Due to the high actuation voltage required to actuate the switch, the electric filed across the dielectric can be higher than $10^{8}$ $\mathrm{V} / \mathrm{m}$. This causes the charges to tunnel from the top and the bottom electrodes into the dielectric. With repeated ON-OFF cycles, charges gradually build up in the dielectric, which shifts the pull-in and pull-out voltages (Figure 1) [28-32]. The amount of the shifting voltage is given in Eq. (10).

$$
\Delta V=\frac{q h Q}{\varepsilon_{r} \varepsilon_{0}}
$$

where $h$ is the distance between the bottom electrode and trapped charge sheet of density $Q, q$ is electron charge and $\varepsilon_{0} \varepsilon_{\mathrm{r}}$ is the permittivity of dielectric.
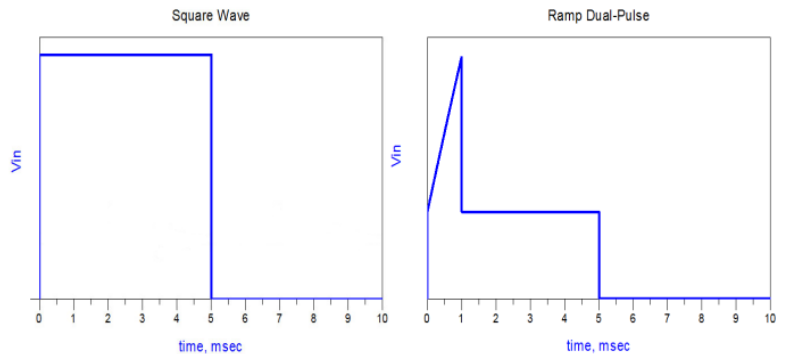

(a)

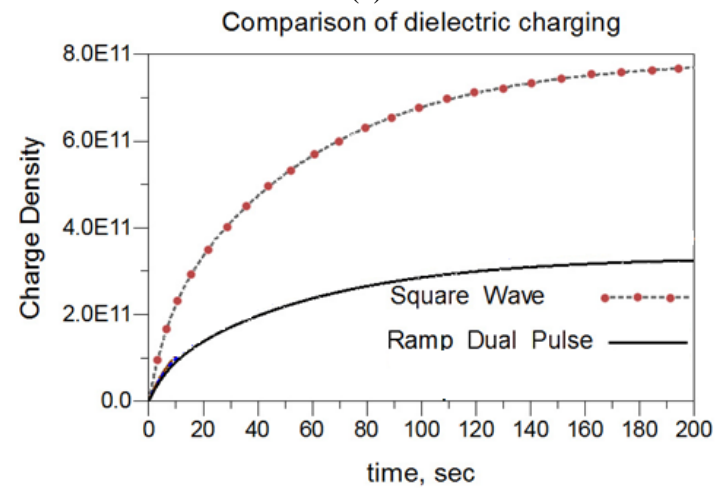

(b)

Figure 2. Comparison of charge effect of driver. (a) Pulse and RDP. (b) Comparing the amount of charge due to the effect of pulse.

This phenomenon becomes very critical at low actuation voltage because it shifts $V_{\text {pull-in }}$ and $V_{\text {pull-out. }}$ This will cause the membrane to actuate by itself without any actuation voltage, or stuck the membrane at down state. In our previous work a new types of voltage driver was introduced to reduce the capacitive charge of MEMS capacitive switches. The ramp dual-pulse (RDP) actuation voltage increases with constant slope at the beginning of the $\mathrm{ON}$ period (Figure 2) instead of the pulse [33]. However, this will have a negative impact on the switching time of MEMS switches.

\section{PROPOSED RF MEMS SWITCH}

The structure of MEMS switch is given in Figure 3. It consists of $\mathrm{CPW}$ that include $\mathrm{GaAs}$ and $2 \mu \mathrm{m}$ thick $\mathrm{Au}$ for providing a minimum insertion loss. Also, the bridge is a low spring constant folded flexure dual fixed with $0.7 \mu \mathrm{m}$ thickness of gold. The top view and cross section of RF MEMS switch is shown in Figure 3.

\subsection{RF Parameters}

\subsubsection{Design and Simulation of RF MEMS Switch for} 4-24 GHz

The first step is to calculate the effective area between the $50 \Omega$ CPW (W=80 $\mu \mathrm{m}$ and $\mathrm{G}=60 \mu \mathrm{m}$ ) and a bridge. According to Eq. (1), the $\mathrm{Cu}$ should be less than $83 \mathrm{fF}$ at $24 \mathrm{GHz}$. The parameters and values of the MEMS switch are given in Table I by using Eq. (11) and details in references [34, 35].

$$
C_{u}=K \frac{\varepsilon_{0} A}{g_{0}}
$$

Table 1. RF MEMS switch parameters.

\begin{tabular}{|c|c|}
\hline Parameter & Value \\
\hline Membrane width (w) & $185 \mu \mathrm{m}$ \\
\hline Membrane length (L) & $220 \mu \mathrm{m}$ \\
\hline Signal line width $(\mathrm{W})$ & $120 \mu \mathrm{m}$ \\
\hline Gap between signal line and ground $(\mathrm{G})$ & $80 \mu \mathrm{m}$ \\
\hline Overlap area & $185 \times 120 \mu \mathrm{m}^{2}$ \\
\hline CPW thickness & $2 \mu \mathrm{m}$ \\
\hline Dielectric thickness & $1000 \AA$ \\
\hline Gap between TL and membrane $\left(\mathrm{g}_{0}\right)$ & $2 \mu \mathrm{m}$ \\
\hline Bridge thickness & $0.7 \mu \mathrm{m}$ \\
\hline HR silicon substrate constant $(\varepsilon)$ & 11.6 \\
\hline Fringing constant $(\mathrm{K})$ & 1.4 \\
\hline
\end{tabular}

Figure 4 shows the simulation result of MEMS shunt switch according to the physical structure of MEMS switch with electromagnetic 3 dimension simulator (EM3DS). It can be seen that the MEMS switch provides a good isolation and insertion loss at up and down state $\left(S_{11}\right.$ and $\left.S_{21} \leq-10 \mathrm{~dB}\right)$ for $4-24 \mathrm{GHz}$. The electrical model and values of RF MEMS switches are given in Figure 4(b). The simulation results by Genesys show a perfect agreement between the physical structure and lumped model at both up and down state position.

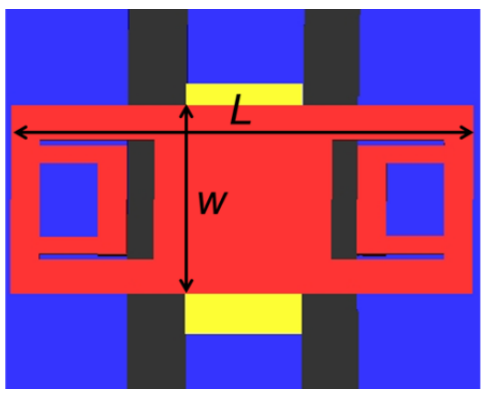

(a)

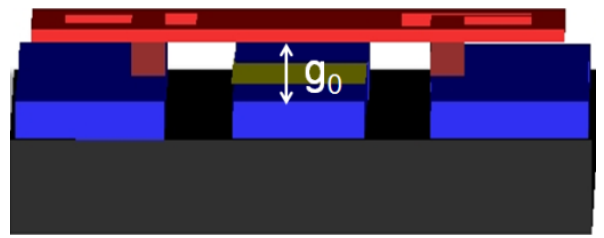


(b)

Figure 3. RF MEMS capacitive shunt MEMS. It consists of high resistivity (HR) silicon, Au CPW, SiN dielectric, anchor and folded beam. (a) Top view of the switch. $L$ and $w$ are the length and width of beam. (b) Cross section view of the switch. It consists of silicon substrate, $\mathrm{CPW}, \mathrm{SiN}$, anchor and dual fixed beam.

\subsubsection{Improving Isolation of MEMS Switch}

According to the previous discussion the most effective way for improving the isolation is to increase the gap or reduce the up state capacitance between transmission line and bridge. However, this increases the actuation voltage of MEMS switch. In this design we increase the isolation by providing a perfect matching between input and output. T matching is one effective method for cancelling the capacitance behavior of MEMS switch in order to make a resonant frequency at the entire frequency band.

The $\mathrm{T}$ match circuit consists of two transmission line (50 and 100 $\mathrm{ohm}$ ). The $50 \Omega$ transmission line is used for MEMS switch which we discussed earlier and high impedance transmission line for matching (L). The electrical circuit of switch at up state is shown in Figure 5. The length of short high impedance transmission line (SHITL) for $Z_{h}=100 \Omega$ can be calculated by Eq. (12).

$$
\tan (\beta l)=\frac{Z_{h}^{2}-Z_{0}^{2} \pm \sqrt{\left(Z_{h}^{2}-Z_{0}^{2}\right)^{2}-\left(\omega C_{u} Z_{h}^{2} Z_{0}\right)^{2}}}{\omega C_{u} Z_{h}^{3}}
$$

where $Z_{0}=50 \Omega, Z_{h}=100 \Omega, C_{u}=0.11 \mathrm{pF}, \mathrm{f}=10 \mathrm{GHz}$. Two values are found for 1 but due to the variation of the phase shift along the

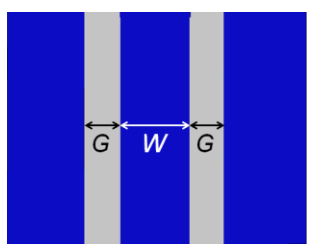

(a)

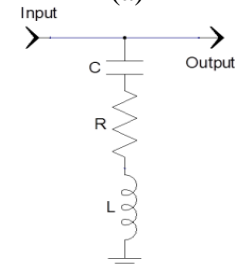

(b)

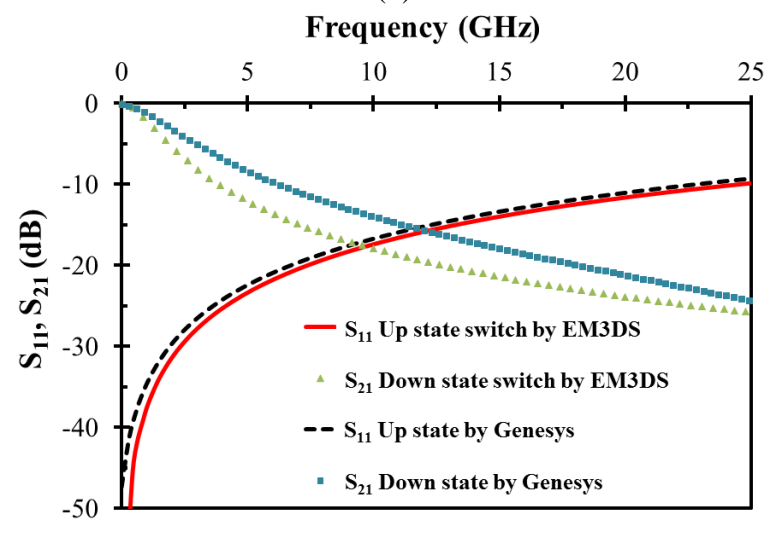

(c)
Figure 4. (a) A $50 \Omega \mathrm{CPW}, \mathrm{W}$ is the wide of signal line and $\mathrm{G}$ is the gap between the signal and ground lines $(80$ and $60 \mu \mathrm{m}$ respectively). (b) Lumped electrical models of MEMS capacitive shunt switch for both up and down state. $\mathrm{C}_{\mathrm{u}}$ is $91 \mathrm{fF}$, $C_{d}$ is $2.87 \mathrm{pF}, \mathrm{L}$ is $4.3 \mathrm{pH}$ and $\mathrm{R}$ is $0.04 \Omega$. (c) Comparing $S_{11}$ and $S_{21}$ for up and down states for both physical structure and electrical lumped model with EM3DS and Genesys.

transmission line, the shorter value is selected because it makes the circuit less sensitive to frequency band $(l=230 \mu \mathrm{m})$. The scattering parameters show that this switch provides a very high isolation $S_{11}$ less than $-20 \mathrm{~dB}$ for the frequency of up to $24 \mathrm{GHz}$. Furthermore, there is a desirable matching at $20 \mathrm{GHz}$ for $\mathrm{S}_{11}$ less than $-32 \mathrm{~dB}$. Also, the $S_{11}$ and $S_{21}$ down-state position for the switch are desirable for the frequency more than $4 \mathrm{GHz}$. The electrical circuit at up state is shown in Figure 5. The value of intrinsic $\mathrm{C}_{\mathrm{TL}}$ and $\mathrm{L}_{\mathrm{TL}}$ of high impedance transmission line is given in Eq. (13) and Eq. (14) $(20 \mathrm{fF}$ and $0.2 \mathrm{nH})$ :

$$
\begin{aligned}
L & =\frac{Z \beta l}{\omega} \\
C & =\frac{\beta l}{Z \omega}
\end{aligned}
$$

$\mathrm{C}_{\mathrm{u}}$ for this MEMS switch consists of $2 \mathrm{C}_{\mathrm{TL}}$ and $\mathrm{C}_{\text {bridge }}$ at up state. The value of electrical model of MEMS switch at up and down state is given in Figure 5. The simulation results by Genesys show a perfect agreement between the physical structure and lumped model in both up and down state position.

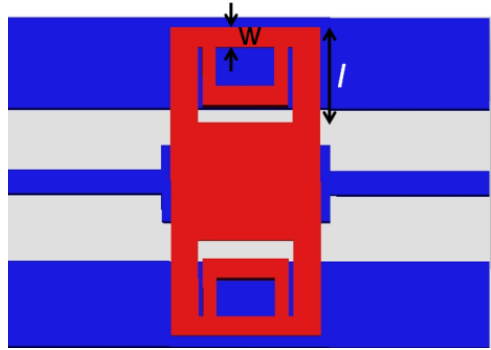

(a)

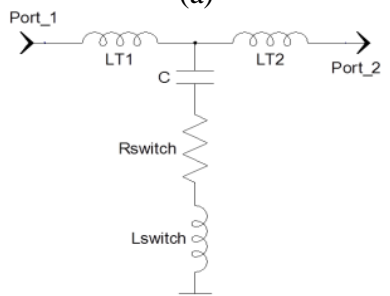

(b)

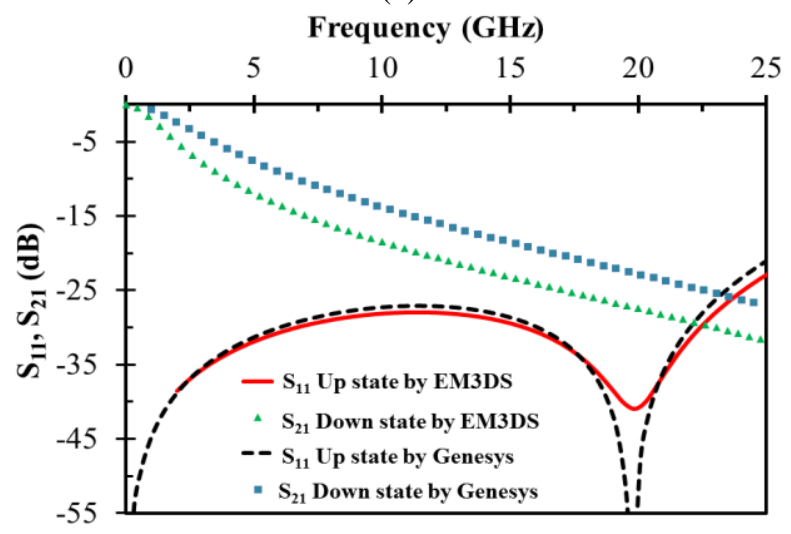

(c) 
Figure 5. (a) Physical structure of MEMS switch with additional two short high impedance transmission lines. (b) Lumped electrical models of MEMS capacitive shunt switch for both up and down state. $\mathrm{C}_{\mathrm{u}}$ is $131 \mathrm{fF}, \mathrm{C}_{\mathrm{d}}$ is $3.5 \mathrm{pF}, \mathrm{L}$ is 4.3 pH and $R$ is $0.04 \Omega$. (c) Comparing $S_{11}$ and $S_{21}$ for up and down state for both physical structure and electrical lumped model with EM3DS and Genesys.

\subsection{Mechanical Parameters}

The actuation voltage should be less than 15 volts; therefore the spring constant should be close to $24 \mathrm{~N} / \mathrm{m}$ (Eq. (8)). The spring constant of the folded flexure MEMS switch is given in Eq. (15).

$$
k=2 E w\left(\frac{t}{l}\right)^{3}
$$

where $\mathrm{E}$ is Young's modulus ( $80 \mathrm{GPa}), \mathrm{t}$ is the thickness $(0.7 \mu \mathrm{m})$, $\mathrm{w}$ is the width of truss $5 \mu \mathrm{m}$ and 1 is $22.5 \mu \mathrm{m}$. As discussed, the beam has an infinite number of modes and it is very important to load the beam in the associated mode. The first three natural frequencies for this beam are simulated by CoventorWare and shown in Figure 6. As can be seen, the direction of the movement for the first resonant is suitable for the RF MEMS switch

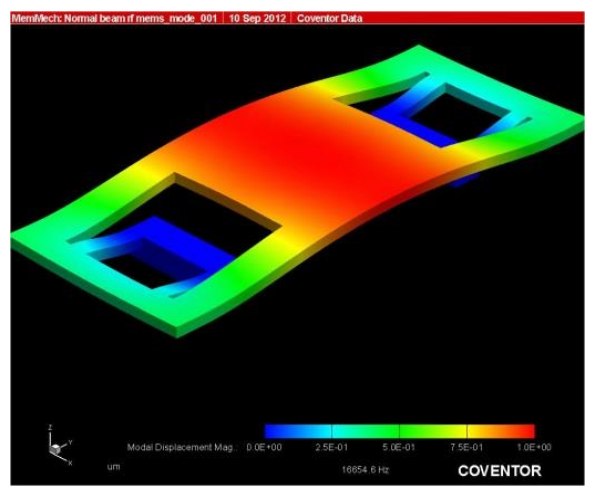

(a)

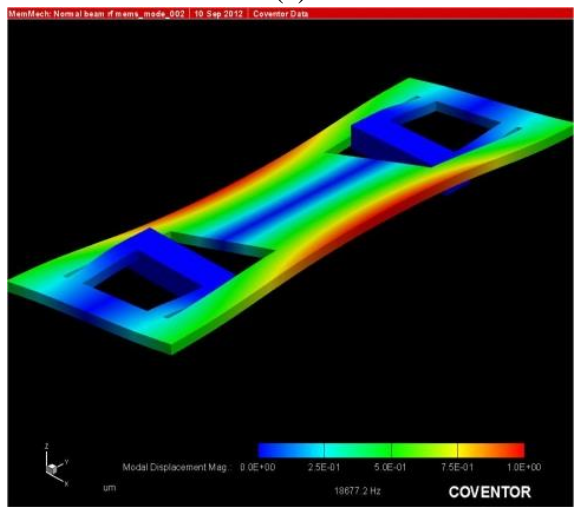

(b)

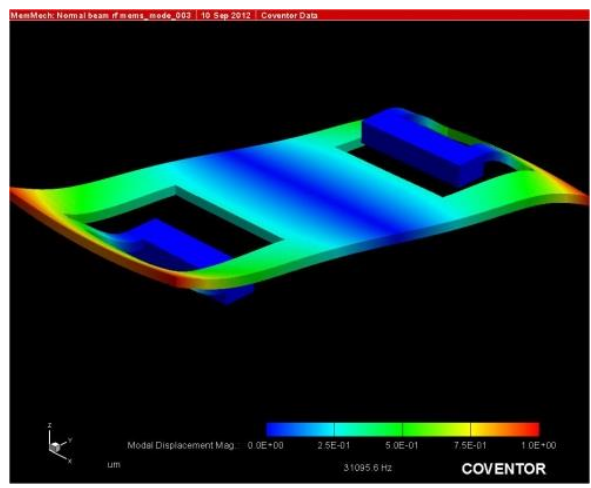

(c)

Figure 6 The first three natural frequency of the beam for the mass and $\mathrm{k}$ of $2.2 \times 10^{-10} \mathrm{Kg}$ and $24 \mathrm{~N} / \mathrm{m}$, respectively. (a) First mode natural frequency is $52567 \mathrm{~Hz}$. (b) Second mode natural frequency is $58952 \mathrm{~Hz}$. (c) Third mode natural frequency is $98148 \mathrm{~Hz}$.

$(52567 \mathrm{~Hz})$ while the other modes does not provide overlap between the transmission line and bridge. Therefore, the mechanical parameters of MEMS switch should be calculated for this frequency. According to the Eq. (6) and Eq. (7), the switching $\mathrm{ON}$ and OFF time are $8.75 \mu \mathrm{s}$ and $4.75 \mu \mathrm{s}$, respectively.

\subsection{Reliability}

Ramp dual-pulse is the method to enhance the lifetime of the switch. For this particular switch, the simulation result shows the comparison of actuation-voltage shift between a $100 \mathrm{~Hz}$ square actuation signal and a $100 \mathrm{~Hz}$ RDP actuation signal with equal duty cycles (Figure 2(a)). Figure 7 shows the compare the shifted $\mathrm{C} / \mathrm{V}$ curve by square and RDP waveform. It is seen that the actuation voltage shifts is reduced from 2.6 to $1.3 \mathrm{~V}$.

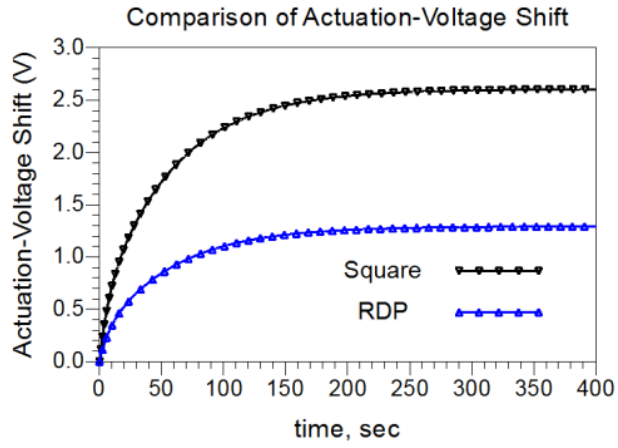

(a)

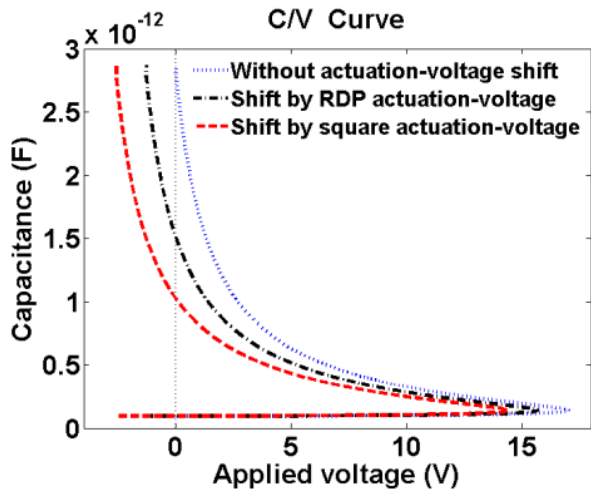

(b) 


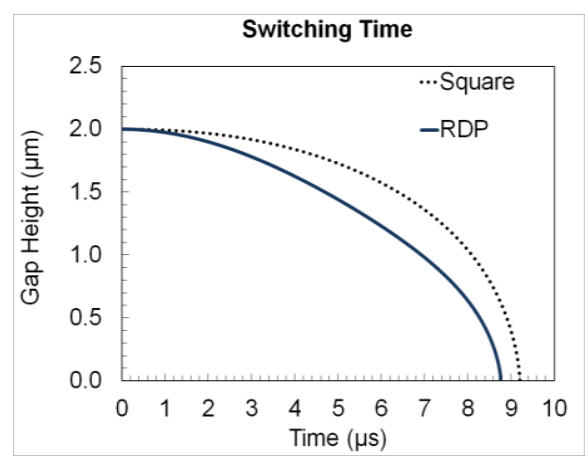

(c)

Figure 7. (a) Comparison of the actuation-voltage shift between square and RDP. (b) $\mathrm{C} / \mathrm{V}$ curve shift by square and RDP actuation voltage. (c) Effects of the actuation signal waveform on the switching time.

Displacement is usually discussed in terms of some functions, such as time. This variable can be obtained using numerical integration from equations motion [36]. Figure 7c compare the time-domain response for the proposed switch under applied voltages which is gained by Mathematica and results are agrees well with CoventorWare. Square and RDP switching times are approximately $8.75 \mu \mathrm{s}$ and $9.2 \mu \mathrm{s}$, respectively. In square waveforms, maximum voltage occurs immediately, whereas the RDP waveform gradually increases the actuation voltage, therefore the membrane reaches the contact later than the square waveform.

\section{CONCLUSIONS}

This paper explained in details how to design a low ES actuationvoltage MEMS switch for C-K band. Two short high impedance transmission lines were designed and included at both ends of the transmission line in order to improve the matching at the entire frequency band at the up-state. Simulations are carried out using ElectroMagnetic 3D Simulator (EM3DS) and CoventorWare to calculate the electrical and mechanical parameters. Return loss and isolation are better than $26 \mathrm{~dB}$ and $20 \mathrm{~dB}$ at both up and down states respectively. The calculated pull-in voltage was almost $15 \mathrm{~V}$ and the mechanical resonant frequency equaled $52 \mathrm{kHz}$. Moreover, the major problem on reliability of MEMS switches is due to the shifting voltage because of the accumulation of trapped charges on the dielectric. This failure is improved by applying a type of driver which generates a ramp dual-pulse. This driver can be easily implemented by electronic devices.

\section{REFERENCES}

[1] K.J. Park, S.M. Kang, H.S. Kim, C.W. Baek, T.K. Chung, Energy scavenging system utilising MEMS switch for power management, Electronics Letters, 48 (2012), 948-949.

[2] S. Zhang, W. Su, M. Zaghloul, Design and Simulation of a Thermally Actuated MEMS Switch for Microwave Circuits, International Journal of RF and Microwave Computer-Aided Engineering, 19 (2009), 492-501.

[3] P. Gammel, G. Fischer, J. Bouchaud, RF MEMS and NEMS Technology, Devices, and Applications, Bell Labs Technical Journal, 10 (2005), 29-60.
[4] G. Rebeiz, K. Entesari, I. Reines, S.J. Park, M. El-tanani, A Grichener, A. Brown, Tuning in to RF MEMS, Microwave Magazine, IEEE, 10 (2009), 55-72.

[5] R. Guerre, U. Drechsler, D. Bhattacharyya, P. Rantakari, R. Stutz, R.V. Wright, Z.D. Milosavljevic, T. Vaha-Heikkila, P.B. Kirby, M. Despont, Wafer-Level Transfer Technologies for PZT-Based RF MEMS Switches, Journal of Microelectromechanical Systems, 19 (2010), 548-560.

[6] C.D. Nordquist, M.S. Baker, G.M. Kraus, D.A. Czaplewski, G.A. Patrizi, Poly-Silicon Based Latching RF MEMS Switch, Microwave and Wireless Components Letters, IEEE, 19 (2009), 380-382.

[7] I.-J. Cho, E. Yoon, Design and fabrication of a single membrane push-pull SPDT RF MEMS switch operated by electromagnetic actuation and electrostatic hold, Journal of Micromechanics and Microengineering, 20 (2010), 035028035035.

[8] S. Gong, H. Shen, N.S. Barker, Study of Broadband Cryogenic DC-Contact RF MEMS Switches, Microwave Theory and Techniques, IEEE Transactions on, 57 (2009), 3442-3449.

[9] C.H. Kim, Mechanically Coupled Low-Voltage Electrostatic Resistive RF Multithrow Switch, Industrial Electronics, IEEE Transactions on, 59 (2012), 1114-1122.

[10] J. Park, E.S. Shim, C. Wooyeol, K. Youngmin, K. Youngwoo, C. Dong-il, A Non-Contact-Type RF MEMS Switch for 24GHz Radar Applications, Journal of Microelectromechanical Systems, 18 (2009), 163-173.

[11] A.Q. Liu, M. Tang, A. Agarwal, A. Alphones, Low-loss lateral micromachined switches for high frequency applications, Journal of Micromechanics and Microengineering, 15 (2005), 157-167.

[12] A. Kundu, S. Sethi, N.C. Mondal, B. Gupta, S.K. Lahiri, H. Saha, Analysis and optimization of two movable plates RF MEMS switch for simultaneous improvement in actuation voltage and switching time, Microelectronics Journal, 41 (2010), 257-265.

[13] C. King Yuk, R. Ramer, RF MEMS Switch with low stress sensitivity and low actuation voltage, in: Antennas and Propagation Society International Symposium, 2009. APSURSI '09. IEEE, 2009, pp. 1-4.

[14] D. Acquaviva, A. Arun, S. Esconjauregui, D. Bouvet, J. Robertson, R. Smajda, A. Magrez, L. Forro, A.M. Ionescu, Capacitive nanoelectromechanical switch based on suspended carbon nanotube array, Applied Physics Letters, 97 (2010), 233508.

[15] M. Dragoman, A. Takacs, A.A. Muller, H. Hartnagel, R. Plana, K. Grenier, D. Dubuc, Nanoelectromechanical switches based on carbon nanotubes for microwave and millimeter waves, Applied Physics Letters, 90 (2007), 113102.

[16] S.W. Lee, D.S. Lee, R.E. Morjan, S.H. Jhang, M. Sveningsson, O.A. Nerushev, Y.W. Park, E.E.B. Campbell, A Three-Terminal Carbon Nanorelay, Nano Letters, 4 (2004), 2027-2030. 
[17] M. Dragoman, D. Dragoman, F. Coccetti, R. Plana, A.A. Muller, Microwave switches based on graphene, Journal of Applied Physics, 105 (2009), 054309.

[18] K.M. Milaninia, M.A. Baldo, A. Reina, J. Kong, All graphene electromechanical switch fabricated by chemical vapor deposition, Applied Physics Letters, 95 (2009), 183105.

[19] M. Liaoa, Y. Koidea, Carbon-Based Materials: Growth, Properties, MEMS/NEMS Technologies, and MEM/NEM Switches, Critical Reviews in Solid State and Materials Sciences, 36 (2011), 66-101.

[20] M. Dequesnes, Z. Tang, N.R. Aluru, Static and Dynamic Analysis of Carbon Nanotube-Based Switches, Journal of Engineering Materials and Technology, 126 (2004), 230-237.

[21] D. Thorby, Structural dynamics and vibration in practice: an engineering handbook, Butterworth-Heinemann, 2008.

[22] S.S. Rao, Mechanical vibrations, Prentice Hall, Englewood Cliffs, 1995.

[23] R.P. LaRose III, K.D. Murphy, Impact dynamics of MEMS switches, Nonlinear Dynamics, 60 (2010), 327-339.

[24] S. Dutta, M. Imran, R. Pal, K.K. Jain, R. Chatterjee, Effect of residual stress on RF MEMS switch, Microsystem Technologies, 17 (2011), 1739-1745.

[25] G.M. Rebeiz, RF MEMS: Theory, Design, and Technology, New Jersey: John Wiley \& Sons, 2003.

[26] M.I. Younis, Sensing and Actuation in MEMS, in MEMS Linear and Nonlinear Statics and Dynamics, Springer, New York, 2011.

[27] S. Lucyszyn, Advanced RF MEMS, Cambridge University Press, New York, 2010.

[28] W.S.H. Wong, L. Chean Hung, Longer MEMS Switch Lifetime Using Novel Dual-Pulse Actuation Voltage, Device and Materials Reliability, IEEE Transactions on, 9 (2009), 569-575.

[29] Y. Xiaobin, P. Zhen, J.C.M. Hwang, D. Forehand, C.L. Goldsmith, A transient SPICE model for dielectric-charging effects in RF MEMS capacitive switches, Electron Devices, IEEE Transactions on, 53 (2006), 2640-2648.

[30] W.M.v. Spengen, Capacitive RF MEMS switch dielectric charging and reliability: a critical review with recommendations, Journal of Micromechanics and Microengineering, 22 (2012), 074001-074023.

[31] Y. Huang, A.S.S. Vasan, R. Doraiswami, M. Osterman, M. Pecht, MEMS Reliability Review, Device and Materials Reliability, IEEE Transactions on, 12 (2012), 482-493.

[32] P. S. Sumant, N. R. Aluru, A. C. Cangellaris, A Compact Model For Dielectric Charging in RF MEMS Capacitive Switches, International Journal of RF and Microwave Computer-Aided Engineering, 19 (2009), 197-203.

[33] M. Zarghami, Y. Mafinezhad, A.Z. Kouzani, K. Mafinezhad, Low actuation-voltage shift in MEMS switch using ramp dual-pulse, IEICE Electronics Express, 12 (2012), 10621068.

[34] Y. Mafinejad, A.Z. Kouzani, K. Mafinezhad, A. Golmakani, Pi-shaped MEMS architecture for lowering actuation voltage of RF switching, IEICE Electronics Express, 6 (2009), 14831489.

[35] Y. Mafinejad, A.Z. Kouzani, K. Mafinezhad, H. Nabovatti, Design and simulation of a low voltage wide band RF MEMS switch, in: Systems, Man and Cybernetics, 2009. SMC 2009. IEEE International Conference on, 2009, pp. 4623-4627.

[36] V. Kaajakari, Closed form expressions for RF MEMS switch actuation and release time, Electronics Letters, 45 (2009), 149-150. 